\title{
MALNUTRITION AMONG THE CHILDREN IN RURAL AREA - A STUDY
}

\author{
Bonde S.W. \\ Hutatma Rashtriya Arts and Science College, Ashti, Wardha (M.S) India \\ Email: sushamakharabe@gmail.com
}

\begin{abstract}
Malnutrition is a very serious problem not only found in India but in world. In fact various schemes have been launched by the government to get rid off this problem. Some organizations like UNICEF, FAO, WHO and NGO's are working in India. "Malnutrition is a condition which occurs when there is a deficiency of certain vital nutrients in a person's diet". The present study deals with the study of malnutrition among the Anganwadi students in the rural area of Ashti Taluka, Dist. Wardha (M.S.) 50 children from Anganwadi in Ashti taluka were chosen for information collection. The present investigation shows that about $74 \%$ children regularly attend Anganwadi still they are facing the problem of malnutrition due to poverty, unhealthy family environments, illiteracy of parents, lack of medical aid, uncleanliness, superstition etc. Therefore, it is very necessary to implement various government schemes effectively and successfully by various departments to bring malnutrition under control.
\end{abstract}

Keywords: Malnutrition, Children, Rural, Problem, Health

\section{Introduction:}

Malnutrition is found to be one of the serious problems in India. In fact, various schemes have been launched by the government to get rid off this problem. The Anganwadi scheme, launched nearly before 33 years, is one of them. Unfortunately, this scheme, like many other, failed to achieve its goal. In fact, the rational evaluation of this scheme hasn't been carried out yet. The World Health Organization (W.H.O.) has issued a serious warning emphasising the fact that malnutrition has become a big challenge for the world. So every individual needs to ponder over the factors responsible for creating this problem. So, people's participation is much essential along with government's endeavour to eradicate malnutrition in India. Almost $40 \%$ of Indian children are underweight and 45 $\%$ are stunted due to malnourishment according to the National Family Health Survey-3. The survey also reported that six out of every 10 children from the poorest house holds are stunted and almost as many are underweight.

It's a known fact that only a healthy generation can contribute substantially to the progress of its nation. Healthy children are supposed to be the assets of a nation. We are in the 21 st century and India is striving to emerge as the super power.
Progress of science has resulted in astonishing industrial developments in India but, the diet related issues in the country, giving birth to malnutrition, haven't been properly addressed. Especially, the problem of malnutrition in our country has arrested attention of the world.

\section{What is Malnutrition?}

"Malnutrition means either inadequate or no supply of nutrition to the body". When an individual doesn't get all essential nutrients as per physical need in adequate and balance form (getting some ingredients in excess or some in less quantity), the side effects on human body are clearly visible and that can be termed as malnutrition.

\section{Symptoms of Mannutrition:}

The most common symptom of malnutrition is weight loss in example those who loss up to $10 \%$ of their body weight in 3 months without dieting are considered to be malnourished. They may other symptoms like fatigue, lack of energy, lack of strength, breathlessness, anemia, change of skin, hair and nails etc. in person with malnutrition. Children with malnutrition additionally show irritability, inability to concentrate, failure to grow to their expected height stunted growth, the abdomen is swollen etc. Malnutrition adversely affects overall development of a child. In fact, pathetic 
condition of a mother is chiefly responsible for tragic condition of a malnutrient child.

\section{Objectives :}

1. To find out the effects of malnutrition on child-development.

2. To trace the causes of malnutrition.

3. To extend the remedial guidance for lowering down the rate of malnutrition.

4. To know about the cleanliness habits of the Anganwadi children.

\section{Assumptions:}

1. Children don't get adequate balance diet.

2. Children attend Anganwadi regularly.

3. Children observe cleanliness.

4. Health service is provided to these children on time.

\section{Research Methodology:}

\section{Analysis of Facts}

\begin{tabular}{|c|c|c|c|c|c|c|c|}
\hline S.N. & Statements & Agree & Percentage & Disagree & Percentage & Total & Percentage \\
\hline 1. & $\begin{array}{l}\text { The children regularly attend } \\
\text { Anganwadi. }\end{array}$ & 37 & $74 \%$ & 13 & $26 \%$ & 50 & $100 \%$ \\
\hline 2. & $\begin{array}{l}\text { The children don't take the } \\
\text { nutritious diet provided in } \\
\text { Anganwadi. }\end{array}$ & 15 & $30 \%$ & 35 & $70 \%$ & 50 & $100 \%$ \\
\hline 3. & $\begin{array}{l}\text { The children get health related } \\
\text { services and facilities. }\end{array}$ & 17 & $34 \%$ & 33 & $66 \%$ & 50 & $100 \%$ \\
\hline 4. & $\begin{array}{l}\text { The children come in Anganwadi by } \\
\text { taking breakfast at home. }\end{array}$ & 17 & $34 \%$ & 33 & $66 \%$ & 50 & $100 \%$ \\
\hline 5. & The children are neat and clean. & 29 & $58 \%$ & 21 & $42 \%$ & 50 & $100 \%$ \\
\hline 6. & The children play in Anganwadi. & 30 & $60 \%$ & 20 & $40 \%$ & 50 & $100 \%$ \\
\hline
\end{tabular}

With respect to statement no. 1 from above table, it was found that $74 \%$ children regularly attend Anganwadi as they get a chance to play with their new makes. $26 \%$ of them are irregular in attendance. $70 \%$ of the children eat the meal provided in Anganwadi and 30\% of them are found to be reluctant to take this diet as they don't find it tasty.

$34 \%$ of the respondents agree with the statement that health related aid is provided on time as monthly health check up is carried out in Anganwadi regularly. However, $66 \%$ of them disagree with this statement because such health facility is not provided daily and they don't get necessary medical facility.

$34 \%$ of the respondents agree with the statement that children take breakfast at home before coming to Anganwadi. But, $66 \%$ respondents disagree with this. Owing
The present study is about malnutrition found among Anganwadi students in the rural area of Ashti taluka. The researcher has selected the research plan and the topics included in the research plan are sample selection, data collection, data analysis and conclusion on the basis of analysis.

\section{Sample Selection:}

In the present study, the Anganwadi children in rural area of Ashti taluka have been selected as the 'unit'. For sample, 50 children are selected by Random sample type from sample selection method.

\section{Fact Collection:}

The information gathered for the present study is related to oral answers received from the respondent. For this purpose, Interview Schedule Technique (?) has been employed. to poverty they don't get adequate food at home.

As far as cleanliness is concern, it was observed that $58 \%$ of the children were found observing cleanliness, but $42 \%$ of them were found in snabby clothes, with uncleaned nails etc.

$60 \%$ of these children were found interested and engaged in outdoor and indoor games but $40 \%$ of them were found reluctant to play. Some of these children preferred either idle sitting or weeping.

To minimize the rate of malnutrition in the state, the State Government has been providing nutritious diet to the Anganwadi children. But the children attend the Anganwadi without breakfast so they it. So the statement that the children do not get proper balance diet is found incorrect.

The health check-up of Anganwadi children is carried out once in a month. So 
in case of their casual illness or an accident, these children cann't get timely medical treatment at Anganwadi. Thus, the statement that the regular medical service is provided to the children in Anganwadi is false.

Owing to poverty, the parents of Anganwadi children are unable to purchase adequate food items. So most of these children don't get proper morning breakfast at home. Though few of them get it at home but it is usually consist of stale food. So the statements that the children come to Anganwadi by taking breakfast at home is found incorrect.

Again, from the observation, it was found that barring few exceptions, most of the children were found having clean and trimmed nails and wearing clean clothes. So the assumption that the children observe cleanliness is correct.

Some of the children were found playing outdoor games and some were engaged in indoor genre. Among the outdoor games, children were found enjoying the games like Hide and Seek, Touch and Go, One-legged Chase etc. On the other hand, some of them were playing with the wooden blocks in the classroom. So, the assumption that the children play in Anganwadi is correct.

\section{Conclusions :}

1. From above survey, it is noticed that some of these children don't eat the nutritious diet provided in Anganwadi and so they are found malnourished.

2. As these children in rural area can't get timely medical aid from the medical practioners, the rate of ailment is high among them.

3. Most of the children attend Anganwadi without taking breakfast at home. Although very few of them have it at home but it's in the form of either stale food or some popular cheap, packaged junk food and snacks. As a result, their body do not get proper nourishment and malnutrition occurs in them.

4. Uncleanliness is found among some of the children. Their unclean clothes, untrimmed nails, snotty nose etc may make them susceptible to many infectious diseases. Consequently, they may fall victim to malnutrition.
5. Financial condition and family environment are mainly responsible for malnourishment of children. In addition to the financial condition i.e. income of a family, superstitions, ignorance, illiteracy of parents, impact of traditions and customs and unhealthy atmosphere both inside and outside the home are some other factors responsible for malnutrition.

\section{Remedies :}

1. It's very much necessary that various government schemes be implemented effectively and successfully by Panchayat Samiti, Revenue Department and other agencies to bring malnutrition under control.

2. The government should enhance and maintain the qualitative standard of its popular scheme "Maata Bal Sangopan" for proper nurturing of the mother and the child.

3. Role of Primary Health centres is very significant in rural area to get rid off the problem of malnutrition. Various awareness programmes concerning nutritious diet, eradication of superstitions, maintenance of hyginic environment etc can effectively be organized.

4. Extensive vaccination drive be carried out from time to time to protect the children from contagious diseases.

5. Benefits of various government schemes must be reached out to the rural area with the help of non-government organizations.

6. Government should provide guaranteed employment to enhance family income.

7. Government should extend substantial support to form the self-help groups.

\section{Remedies at family level :}

1. Mothers should nourish their babies with adequate nutritious diet. Instead of stale and uncovered food, children be served fresh cooked meal.

2. Complementary and alternative food items should be used in diet. Seasonwise local as well as available vegetables and fruits be included in the diet.

3. Mothers must observe cleanliness norms and teach and comple children to follow them.

4. If we really wish to get rid off the problem of malnutrition then it's very 
necessary to bring about a very positive change in the temperament of the rural people. Unless the temperament of the rural people get changed, no effort can yield fruitful results.

\section{References}

Poshan Aani Aahar - Prof. Triveni D.

Farkade and Prof. Sulabha S. Gonge

Aahar Aani Poshan - Prof. Mrs. Minakshi

Tarnekar

Aaroyga Sahajivan Aani Aahar - Dr. D. R.

Tambe

www.google.co.in 